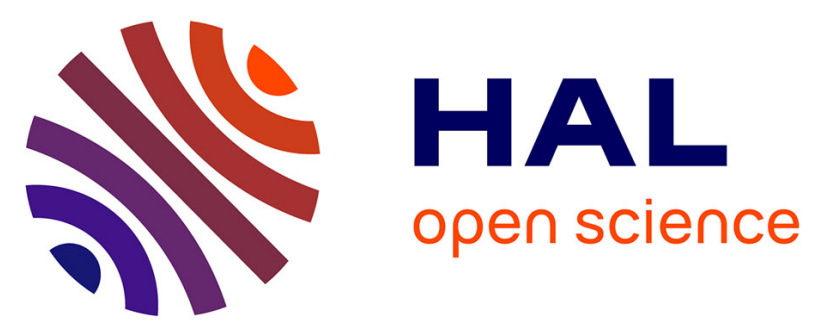

\title{
Accelerated ultraviolet aging of structural and luminescent properties of the ureasil-polyether hybrid materials U-PEO:Eu3+ and U-PPO:Eu3+
}

Gustavo Palácio, Damien Boyer, Sandrine Therias, Sandra Pulcinelli, Rachid Mahiou, Geneviève Chadeyron, Celso Santilli

\section{To cite this version:}

Gustavo Palácio, Damien Boyer, Sandrine Therias, Sandra Pulcinelli, Rachid Mahiou, et al.. Accelerated ultraviolet aging of structural and luminescent properties of the ureasil-polyether hybrid materials U-PEO:Eu3+ and U-PPO:Eu3+. Polymer, 2019, 177, pp.102-110. 10.1016/j.polymer.2019.05.060 . hal-02191247

\section{HAL Id: hal-02191247 \\ https://hal.science/hal-02191247}

Submitted on 8 Dec 2020

HAL is a multi-disciplinary open access archive for the deposit and dissemination of scientific research documents, whether they are published or not. The documents may come from teaching and research institutions in France or abroad, or from public or private research centers.
L'archive ouverte pluridisciplinaire HAL, est destinée au dépôt et à la diffusion de documents scientifiques de niveau recherche, publiés ou non, émanant des établissements d'enseignement et de recherche français ou étrangers, des laboratoires publics ou privés. 


\title{
Accelerated ultraviolet aging of structural and luminescent properties of the ureasil-polyether hybrid materials U-PEO: $\mathrm{Eu}^{3+}$ and U-PPO: $\mathrm{Eu}^{3+}$
}

\author{
Gustavo Palácio, ${ }^{\mathrm{a}, \mathrm{b}}$ Damien Boyer, ${ }^{\mathrm{b}}$ Sandrine Therias, ${ }^{\mathrm{b}}$ Sandra H. Pulcinelli, ${ }^{\mathrm{a}}$ Rachid Mahiou, ${ }^{\mathrm{b}}$ Geneviève Chadeyron, ${ }^{\mathrm{b}}$ and \\ Celso V. Santilli ${ }^{b^{*}}$ \\ ${ }^{a}$ Chemistry Institute of São Paulo State University - UNESP, 14800-060 Araraquara, São Paulo, Brazil \\ b Université Clermont Auvergne, CNRS, SIGMA Clermont, Institut de Chimie de Clermont-Ferrand, F-63000 Clermont- \\ Ferrand, France \\ * Corresponding author: Chemistry Institute of São Paulo State University - UNESP, 14800-060 Araraquara, São Paulo, Brazil. e-mail \\ address: cv.santilli@iq.unesp.br
}

KEYWORDS: Organic-inorganic hybrid materials, polyether, sol-gel, photooxidation, photoluminescence.

\section{HIGHLIGHTS:}

- $\quad$ Formate was the main photoproduct formed during the ultraviolet aging of ureasil-polyether hibrid (U-PEO and U-PPO).

- In $\mathrm{Eu}^{3+}$ doped hybrid (U-PEO:Eu ${ }^{3+}$ and U-PPO:Eu ${ }^{3+}$ ) a concomitant decreases of the $\mathrm{Eu}^{3+}$ complexed to urea bridges, the spatially correlated siloxane nodes, and the Judd-Ofelt parameter $\Omega_{2}(\mathrm{R})$ were observed during the photodegradation process

- The sensitivity of structural features and PL properties arising from the photoinduced degradation of ureasil-polyether films could be exploited in the fabrication of new transparent, flexible, and biocompatible UV dosimeters and sensors.

\begin{abstract}
In this paper, we evaluate the role played by the polyether type and chain length on the complexation of Eu ${ }^{3+}$ by the urea group of siloxane-polyether organic-inorganic hybrid materials based on polyethylene oxide $\left(\mathrm{U}-\mathrm{PEO}, \mathrm{mw}=1900 \mathrm{~g} \cdot \mathrm{mol}^{-1}\right)$ and polypropylene oxide (U-PPO, $\mathrm{mw}=230,2000$, and $4000 \mathrm{~g} \cdot \mathrm{mol}^{-1}$ ). Investigation was made of the effect of the photooxidation of the PEO and PPO chains, induced by artificially accelerated ultraviolet aging $(\lambda \geq 300 \mathrm{~nm})$, with the decomplexation of $\mathrm{Eu}^{3+}$ from the urea-polyether array. Fourier transform infrared (FTIR) and photoluminescence (PL) spectra evidenced loss of the ligand-to-metal charge transfer (LMCT) when the $\mathrm{Eu}^{3+}$ cations were unable to disrupt the strong hydrogen-bonded urea/urea aggregates formed using shorter U-PPO chains (230 g.mol ${ }^{-1}$ ) or semicrystalline U-PEO (1900 g. $\mathrm{mol}^{-1}$ ). FTIR analysis showed that formate was the main photoproduct formed continuously during the artificial ultraviolet aging of U-PEO (1900 g. $\left.\mathrm{mol}^{-1}\right)$ and U-PPO (2000 g.mol ${ }^{-1}$ ), with concomitant decreases of Eu ${ }^{3+}$ complexed to urea bridges, spatially correlated siloxane nodes, and the Judd-Ofelt parameter $\Omega_{2}(\mathrm{R})$. The kinetics of all these parameters were described by exponential laws with comparable time constants, evidencing the sensitivity of the Eu ${ }^{3+}$ photoluminescence to the elimination/formation of the hydrogen-bonded urea-polyether array during the photooxidation of PPO chains. In the case of UPEO: $\mathrm{Eu}^{3+}$, different time constant values were observed, indicating the existence of a faster process governed by the facilitated transport of the oxidative species through the amorphous moieties of the semicrystalline U-PEO. This sensitivity of structural and PL properties arising from the photoinduced degradation of ureasil-polyether films can be exploited in the fabrication of new transparent, flexible, and biocompatible UV dosimeters and sensors.
\end{abstract}

\section{Introduction}

The combination of lanthanide compounds and organic-inorganic hybrids (OIHs) provides the benefits of the intrinsic characteristics of sol-gel derived host materials (such as processability, mechanical, thermal, and chemical stability[1-3], and biocompatibility) and the outstanding luminescent properties of lanthanide compounds (such as line-like emissions, long luminescence lifetimes, large Stokes shifts, and high luminescence quantum yields)[4,5]. Research into lanthanide-doped OIH sol-gel materials emerged about thirty years ago, with the use of this soft 
chemistry route to prepare homogeneous and transparent materials with tunable composition and tailored properties[6-8]. In general, the lanthanide ions (Ln) embedded in an OIH host matrix are linked to matrix moieties by specific interactions such as covalent, coordination, electrovalent, dipolar, and hydrogen bonds[9,10]. The existence of specific guest-host (Ln-OIH) coordination sites can overcome the disadvantages of concentration quenching, clustering or aggregation of emitters, inhomogeneity, or poor chemical stability $[4,5,9,11]$.

An important example of the easy tunability of the guest-host interaction site is provided by the Ln-OIH family classified as di-ureasils. These materials present urea bridges between a silicate backbone and polyether (PE) macromers of different molecular weights, known as U$\mathrm{PE}[12,13]$. The hybrids display an intrinsic broad green-blue emission from the urea bridges, as well as emission originating from electron-hole recombination in the siliceous domains of the inorganic backbone[14-16]. The energy transfer from the di-ureasil emitter centers to incorporated $\mathrm{Eu}^{3+}$ ions results in white luminescence constituted of $\mathrm{Eu}^{3+}$ red emission in addition to the broad green-blue emission arising from the hybrid host matrix[17]. Furthermore, the emission color can be tuned across the CIE chromaticity diagram by changing the excitation wavelength, the PE chain length, or the amount of incorporated europium salt[18]. The two latter dependencies are especially related to the higher efficiency of energy transfer to $\mathrm{Eu}^{3+}$ coordinated to the carbonyl groups $\left(\mathrm{O}_{\text {carb }}\right)$ of the urea bridges, which are located near the hybrid host emitting centers, as compared to $\mathrm{Eu}^{3+}$ coordination to ether oxygens of the PE chain[19]. This interesting characteristic has resulted in a large number of studies focused on the design and synthesis of U$\mathrm{PE}: \mathrm{Ln}^{3+}$ for applications in different areas such as chemical sensing, bio-imaging, dye-sensitized photoelectrochemical cells, and organic light-emitting devices (OLEDs)[20-25].

A difficulty of long term application is that organic materials and polymers, such as those used in OIHs, are degraded during their life cycle. Depending on the application, these materials are subjected to environmental aging factors including UV light, adverse temperature, and the atmosphere[26]. Degradation and oxidation of the polymers have several serious effects on their chemical, physical, and mechanical properties including molecular weight, tensile strength, impact strength, and creep, among others[27]. Changes in mechanical properties result from reactions that either reduce the size of molecules or lead to crosslinking between polymer chains to form rigid three-dimensional structures[28]. In this way, chain scission and oxidation reactions can be intimately coupled in polymer degradation and can affect the stability of the OIH: $\operatorname{Ln}^{3+}$ complex, causing loss of the $\mathrm{Ln}^{3+}$ optical properties[19]. The most common mechanisms of polymer degradation are photooxidation and thermooxidation[29-31]. These types of degradation are often triggered by macroradical formation from the abstraction of hydrogen atoms, leading to scission of the main chain[32]. In the case of polyethers such as polyethylene oxide (PEO) and polypropylene oxide (PPO), degradation proceeds by random chain scission, resulting in several oxidation products: esters, aldehydes, and formates[33-36]. The photooxidation and thermooxidation mechanisms are quite similar, differing in terms of the amounts of the main oxidation products. Thermooxidation produces equal amounts of esters and formates, whereas photooxidation generates formates and esters in a ratio of $5: 1[37]$.

In recent work [20] we have demonstrated that specific coordination of $\mathrm{Eu}^{3+}$ to the carbonyl groups $\left(\mathrm{O}_{\text {carb }}\right)$ of the urea bridges and of $\mathrm{Li}^{+}$to the ether-type oxygen $\left(\mathrm{O}_{\text {eth }}\right)$ can be exploited to prepare U-PE materials with multifunctional properties, namely photoluminescence (PL) and 
ionic conduction. This emerging dual functionality was achieved by the co-incorporation of $\mathrm{Eu}^{3+}$ and $\mathrm{Li}^{+}$into $\mathrm{OIH}$ materials based on U-PEO and U-PPO with similar molecular weights (1900 g $\mathrm{mol}^{-1}$ for PEO and $2000 \mathrm{~g} \mathrm{~mol}^{-1}$ for PPO) using a metal molar ratio fixed at $\left[\mathrm{O}_{\text {carb }}\right] /\left[\mathrm{Eu}^{3+}\right]=3$ and $\left[\mathrm{O}_{\text {eth }}\right] /\left[\mathrm{Li}^{+}\right]=15$. Although the degradation of PEO and PPO is well documented [33-36], the photodegradation and the effect of photo ageing on the PL properties of $\mathrm{Eu}^{3+}$ doped materials (UPEO:Eu and U-PPO:Eu) have not been reported. The aim of this study was therefore to investigate the effect of the ultraviolet light irradiation time $(\lambda \geq 300 \mathrm{~nm})$ on the photodegradation of U-PE film prepared with polymer of different nature and molecular weight, and doped with several $\left[\mathrm{O}_{\text {carb }}\right] /\left[\mathrm{Eu}^{3+}\right]$ molar ratios. Special attention was paid to correlate the aging on the PL properties of U-PEO: $\mathrm{Eu}^{3+}$ and U-PPO: $\mathrm{Eu}^{3+}$ materials with the modification of the chemical environment of $\mathrm{Eu}^{3+}$ induced by photo degradation of PE chains. The photodegradation studies were performed under air at atmospheric pressure using an accelerated aging device with $\lambda>300$ $\mathrm{nm}$ (SEPAP12/24). The effects of aging time on the photodegradation products, the OIH nanostructure, and changes of the $\mathrm{Eu}^{3+}$ complexation site were investigated using Fourier transform infrared (FTIR) spectroscopy, small-angle X-ray scattering (SAXS), and photoluminescence techniques.

\section{Experimental}

\subsection{Synthesis of the materials}

The OIH materials were synthesized by the sol-gel method, according to a well-known procedure[38]. In brief, the ureasil (U) cross-linking agent IsoTrEOS (3(isocyanatopropyl)triethoxysilane, Sigma-Aldrich, 95\% purity, CAS \#24801-88-5) was covalently bonded to both ends of the different PE macromer by reacting the terminal amino-propyl groups, followed by the sol-gel reaction involving the $\mathrm{Si}(\mathrm{OEt})_{3}$ hydrolysis, followed by the condensation reaction to form ureasil cross-linking nodes. This procedure was adopeted to prepare U-PEO with mw 1900 g.mol ${ }^{-1}$ (Jeffamine ${ }^{\circledR}$ ED-2003), (CAS \#65605-36-9) and UPPO with mw 230 (Jeffamine ${ }^{\circledR}$ D-230), 2000 (Jeffamine ${ }^{\circledR}$ D-2000) and 4000 g.mol ${ }^{-1}$ (Jeffamine ${ }^{\circledR}$ D-4000 (XTJ-510)) (CAS \#9046-10-0) using as reactant Jeffamine ${ }^{\circledR}$ ED-2003, Jeffamine ${ }^{\circledR}$ D-230, Jeffamine ${ }^{\circledR}$ D-2000, and Jeffamine ${ }^{\circledR}$ D-4000, respectively. The doping with different $\mathrm{Eu}^{3+}$ loading was achieved by suitable mass of europium(III) chloride hexahydrate (Fluka, Aldrich, 99.9\% purity, CAS \#1375992-7) dissolved into the $\mathrm{OIH}$ precursor ethanoic solution in order to prepare U-PEO:Eu ${ }^{3+}$ and UPPO: $\mathrm{Eu}^{3+}$ samples with $\left[\mathrm{O}_{\text {carb }}\right] /\left[\mathrm{Eu}^{3+}\right]$ of $0.75,1.5,3.0,4.5$, and 6.0 . Films of $\sim 50 \mu \mathrm{m}$ thick were prepared by casting $\mathrm{OIH}$ sol on a Teflon mould and drying at room temperature $\left(25^{\circ} \mathrm{C}\right)$.

\subsection{Accelerated ultraviolet aging}

The accelerated photodegradation was performed in the presence of air, at $60{ }^{\circ} \mathrm{C}$, in a SEPAP $12 / 24$ device. This apparatus was designed for the study of polymer photodegradation during artificial aging corresponding to moderately accelerated conditions [39]. The device was equipped with four medium-pressure mercury lamps (Mazda MA 400) in a vertical position at one axis of the chamber and the samples were placed on a rotating carousel $13 \mathrm{~cm}$ in diameter, which could hold 24 samples. Wavelengths below $300 \mathrm{~nm}$ were filtered using a glass envelope. The OIH samples were exposed in the form of rectangular films $(2 \times 3 \mathrm{~cm})$ with thickness of $50 \mu \mathrm{m}$. 


\subsection{Characterization techniques}

The FTIR spectra of the OIH films were recorded with a Nicolet 760-FTIR spectrometer operating in transmission mode and controlled with OMNIC software. Spectra were obtained with accumulation of 32 scans and $4 \mathrm{~cm}^{-1}$ resolution.

The absolute quantum yield (AQY) efficiencies and the emission spectra (upon excitation at $365 \mathrm{~nm}$ ) were determined using a C9920-02G PL-QY system (Hamamatsu). This consisted of a $150 \mathrm{~W}$ monochromatized Xe lamp, an integrating sphere (with Spectralon ${ }^{\circledR}$ coating, $\varnothing=3.3$ inches), and a high sensitivity CCD spectrometer for detecting the entire spectral luminescence (the emission spectra were integrated from 576 to $728 \mathrm{~nm}$ for the europium-based compounds). The automatically controlled excitation wavelength range was from 250 to $500 \mathrm{~nm}$, with a resolution bandwidth better than $5 \mathrm{~nm}$. Absolute photoluminescence (PL) quantum yield excitation spectra were obtained by scanning the excitation and monitoring the overall luminescence of $\mathrm{Eu}^{3+}$.

The photooxidized samples were submitted to $\mathrm{NH}_{3}$ chemical treatment in order to identify the photoproducts. The irradiated films were exposed to $\mathrm{NH}_{3}$ gas in all-Teflon vessels, at room temperature, in a simple flow system that could be sealed off to permit the reaction to proceed. In parallel to these treatments, it was observed that the unoxidized samples without $\mathrm{Eu}^{3+}$ loading did not react with the gas. This procedure, which has been described in a previous paper[36], was performed for the photooxidized OIH materials without and with $\mathrm{Eu}^{3+}$ loading.

The nanostructures of the as-prepared $\mathrm{OIH}$ and photooxidized samples were analyzed by small-angle X-ray scattering (SAXS) measurements performed at the SAXS1 beamline of the National Synchrotron Light Laboratory (LNLS, Campinas, Brazil). The beamline was equipped with a 2D Pilatus 300k detector located $910.9 \mathrm{~mm}$ from the sample, recording the image of the scattering intensity, $I(q)$, as a function of the modulus of the scattering vector, $q=4 \pi / \lambda \sin (\varepsilon / 2)$, where $\varepsilon$ is the $\mathrm{X}$-ray scattering angle. The data were normalized considering the varying intensity of the direct X-ray beam, the detector sensitivity, and the sample transmission. The intensity of the parasitic scattering due to the cell windows and vacuum was subtracted from the total scattering intensity.

The Differential Scanning Calorimetry (DSC) measurements were carried out using a Q100 analyzer (TA Instruments. The samples were heated at the rate $5{ }^{\circ} \mathrm{C} / \mathrm{min}$ in the range $-90{ }^{\circ} \mathrm{C}-100$ ${ }^{\circ} \mathrm{C}$, nitrogen was used for the gas purge, supplied at a flow rate of $50 \mathrm{~mL} / \mathrm{min}$. The melting enthalpy $\left(\Delta \mathrm{H}_{\mathrm{m}}\right)$ was recorded during the first heating run. The degree of crystallinity $\left(\mathrm{D}_{\mathrm{C}}\right)$ was calculated from the relationship between $\Delta \mathrm{H}_{\mathrm{m}}$ and the standard melting enthalpy for $100 \%$ crystalline PEO $\left(\Delta \mathrm{H}_{\mathrm{p}}\right)(196.4 \mathrm{~J} / \mathrm{g})$, following the equation: $\mathrm{D}_{\mathrm{C}}(\%)=\left(\Delta \mathrm{H}_{\mathrm{m}} / \Delta \mathrm{H}_{\mathrm{p}}\right) * 100 \%[40]$.

\section{Results and Discussion}

\section{1 $\mathrm{Eu}^{3+}$ complexation in the U-PEO and U-PPO host OIHs}

In order to determine the $\left[\mathrm{O}_{\mathrm{carb}}\right] /\left[\mathrm{Eu}^{3+}\right]$ ratios that provided the best optical efficiencies for the two polyether hybrid materials (U-PEO, with $\mathrm{mw}=1900 \mathrm{~g} \cdot \mathrm{mol}^{-1}$, and U-PPO, with $\mathrm{mw}=2000$ g.mol ${ }^{-1}$ ), the absolute quantum yields (AQY) were determined as a function of the amount of $\mathrm{Eu}^{3+}$, using UV excitation at $365 \mathrm{~nm}$. The results are shown in Figure SI.1 (Supplementary Information). Regardless of the polyether type, the highest AQY values were obtained for 
$\left[\mathrm{O}_{\text {carb }}\right] /\left[\mathrm{Eu}^{3+}\right]=3$, with values of $2.3 \%$ and $8.9 \%$ for U-PEO:Eu ${ }^{3+}$ and U-PPO:Eu ${ }^{3+}$, respectively. The photoluminescence properties of $\mathrm{OIH}$ materials doped with different $\mathrm{Eu}^{3+}$ concentrations were studied by Ribeiro et al.[41] and Bermudez et al.[42]. The results obtained in these studies were similar and indicated that for lower doping concentrations, the dried gels presented distributions of $\mathrm{Eu}^{3+}$ typical of an amorphous environment, while a crystalline-like environment of $\mathrm{Eu}^{3+}$ was observed for higher concentrations. Decreasing radiative decay rates and spectral variations suggested that the transformation of the surrounding $\mathrm{Eu}^{3+}$ environment from amorphous-like to crystalline-like led to quenching of the $\mathrm{Eu}^{3+} \mathrm{PL}$ features. Considering the semicrystalline and amorphous states of U-PEO:Eu ${ }^{3+}$ and U-PPO:Eu ${ }^{3+}$ [20], respectively, this explanation also supports the strong difference of AQY found for the OIHs prepared with polymers of different natures.

Photoluminescence (PL) studies were performed with the OIHs prepared with PE chains of different molecular weights (PPO of 230, 2000, and 4000 g.mol ${ }^{-1}$, and PEO of 1900 g.mol ${ }^{-1}$ ), containing the optimized amount of $\mathrm{Eu}^{3+}\left(\left[\mathrm{O}_{\mathrm{carb}}\right] /\left[\mathrm{Eu}^{3+}\right]=3\right)$. The PL emission spectra recorded upon UV excitation at $365 \mathrm{~nm}$ are displayed in Figure 1a. All the spectra exhibited narrow emission bands arising from $f$ - $f$ transitions of $\mathrm{Eu}^{3+}$ ions from the ${ }^{5} \mathrm{D}_{0}$ excited state to ${ }^{7} \mathrm{~F}_{\mathrm{J}}(\mathrm{J}=0-4)$ ground states. The ${ }^{5} \mathrm{D}_{0} \rightarrow{ }^{7} \mathrm{~F}_{2}$ transition located at $611 \mathrm{~nm}$ led to the strongest emission intensity, conferring a red emission feature to the samples. The broad band in the green-blue spectral range could be ascribed to the convolution of the emission from $\mathrm{NH}$ groups of urea bridges and the emission originating from electron-hole recombination in the siliceous domains in the inorganic backbone[43-45], which have already been observed for unloaded matrices[46] of similar hybrids[14,15]. The latter feature was much stronger for U-PPO: $\mathrm{Eu}^{3+}$ of high molecular weight (2000 and 4000 g. $\mathrm{mol}^{-1}$ ), compared to U-PEO:Eu ${ }^{3+}$ of $1900 \mathrm{~g} \cdot \mathrm{mol}^{-1}$ and U-PPO:Eu ${ }^{3+}$ of 230 g.mol 1 , indicating a significant sensitization of the organic part upon excitation at $365 \mathrm{~nm}$. This suggested that the $\mathrm{Eu}^{3+}$ atoms in U-PPO: $\mathrm{Eu}^{3+}$ of lower chain length were present in a crystallinelike environment similar to that observed for U-PEO:Eu ${ }^{3+}$. This effect of the nature and chain length of the PE was in agreement with the PL excitation spectra showing a broad band centred at $365 \mathrm{~nm}$ for the U-PPO: $\mathrm{Eu}^{3+}$ hybrids of high molecular weight $\left(2000\right.$ and $4000 \mathrm{~g} \cdot \mathrm{mol}^{-1}$ ), when monitoring the $\mathrm{Eu}^{3+5} \mathrm{D}_{0} \rightarrow{ }^{7} \mathrm{~F}_{2}$ transition at $611 \mathrm{~nm}$ (Figure 1b). This band was associated with the ligand-to-metal charge-transfer (LMCT) and occurred in the same energy region of the ${ }^{7} \mathrm{~F}_{0} \rightarrow{ }^{5} \mathrm{~L}_{6}$ (at $395 \mathrm{~nm}$ ) and ${ }^{7} \mathrm{~F}_{0} \rightarrow{ }^{5} \mathrm{D}_{2}$ (at $465 \mathrm{~nm}$ ) transitions, ascribed to the intra-configurational transitions of $\mathrm{Eu}^{3+}$ [17]. This feature was consistent with an antenna effect mechanism[10], indicating efficient transfer from the high energy levels of the ligands to high excited states of the $\mathrm{Eu}^{3+}$ ions. This antenna effect was lower for U-PEO: $\mathrm{Eu}^{3+}$ and for U-PPO:Eu ${ }^{3+}$ of low molecular weight (230 g. $\mathrm{mol}^{-1}$ ). 

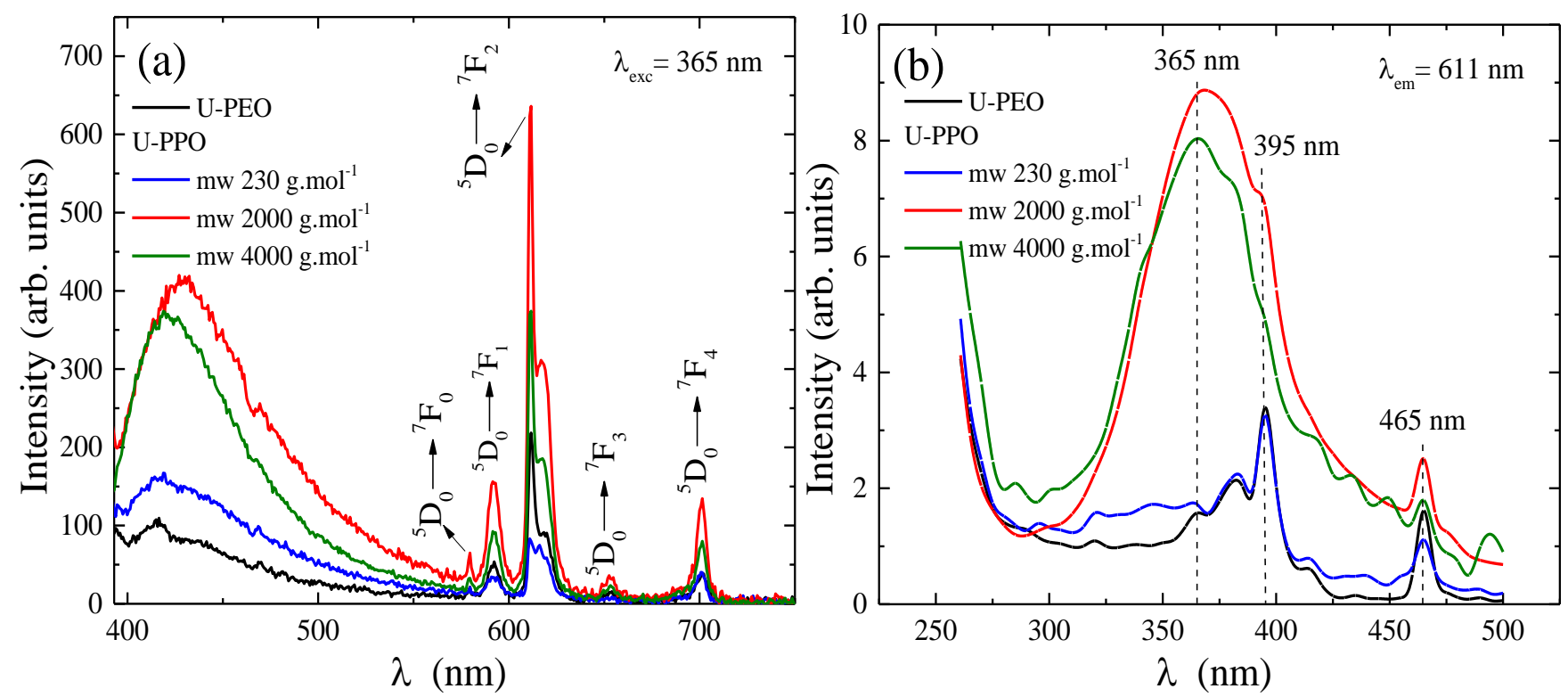

Figure 1: (2-columm fitting image) (a) Emission and (b) excitation spectra before photooxidation $(\mathrm{t}(\mathrm{h})=0)$ for $\mathrm{U}$ PEO: $\mathrm{Eu}^{3+}\left(\mathrm{mw}=1900\right.$ g. $\left.\mathrm{mol}^{-1}\right)$ and U-PPO:Eu ${ }^{3+}$ of different molecular weights $\left(\mathrm{mw}=230,2000\right.$, and $\left.4000 \mathrm{~g} \cdot \mathrm{mol}^{-1}\right)$, with $[\mathrm{Ocarb}] /\left[\mathrm{Eu}^{3+}\right]=3$.

Valuable information concerning the dependency of the chemical environment of the $\mathrm{Eu}^{3+}$ cations on the nature and chain length of the PE could be obtained from the FTIR analysis of the hydrogen bonding signature of this OIH for amide I and amide II, located in the carbonyl regions $\left(1800-1500 \mathrm{~cm}^{-1}\right)$. The FTIR spectra of $50 \mu \mathrm{m}$ thick OIH films, either undoped or doped with $\mathrm{Eu}^{3+}$ at $\left[\mathrm{O}_{\text {carb }}\right] /\left[\mathrm{Eu}^{3+}\right]=3$, are compared in Figure 2. Irrespective of the nature and chain length of the PE, the spectra of all the undoped OIHs presented an envelope composed of three components in the amide I region, at 1717-1721 (weak), 1678-1694 (average), and 1634-1641 $\mathrm{cm}^{-1}$ (intense), together with a single intense band at $1559-1564 \mathrm{~cm}^{-1}$ in the amide II region[15,19,47,48]. Comparison of the spectra evidenced that the changes induced by $\mathrm{Eu}^{3+}$ doping could be classified into two families. In the first, the incorporation of $\mathrm{Eu}^{3+}$ in the high molecular weight hybrids (UPEO:Eu ${ }^{3+}$ and U-PPO:Eu ${ }^{3+}$ of 2000 and $4000 \mathrm{~g} \cdot \mathrm{mol}^{-1}$ ) led to suppression of the two clearly separated bands and the appearance of a single and very intense band at $1608 \mathrm{~cm}^{-1}$, indicative of complexation of the $\mathrm{Eu}^{3+}$ atom by the resonant urea linkage[19,49]. On the other hand, for the UPPO:Eu ${ }^{3+}$ with short polymer chain $\left(230 \mathrm{~g} \cdot \mathrm{mol}^{-1}\right)$, the suppression of the amide I and amide II envelope was not observed, suggesting that the $\mathrm{Eu}^{3+}$ atoms were unable to disrupt the strongly hydrogen-bonded urea-urea aggregates[50], resulting in a negligible quantity of free urea groups available for $\mathrm{Eu}^{3+}$ coordination. This could provide an explanation for the lower LMCT efficiency observed for U-PPO:Eu ${ }^{3+}$ with shorter chains, but did not apply for U-PEO:Eu ${ }^{3+}$. In the latter case, the lower LMCT efficiency could be a consequence of the low amount of disordered UPEO: $\mathrm{Eu}^{3+}$-urea associations resulting from the semicrystalline state of the U-PEO matrix [19]. Given these distinct classes of PL properties, an in-depth structural/optical study of the UPEO:Eu ${ }^{3+}$ and U-PPO:Eu ${ }^{3+}\left(2000\right.$ g.mol $\left.{ }^{-1}\right)$ was performed in order to elucidate the modifications induced by exposure to UV light, as discussed below. 

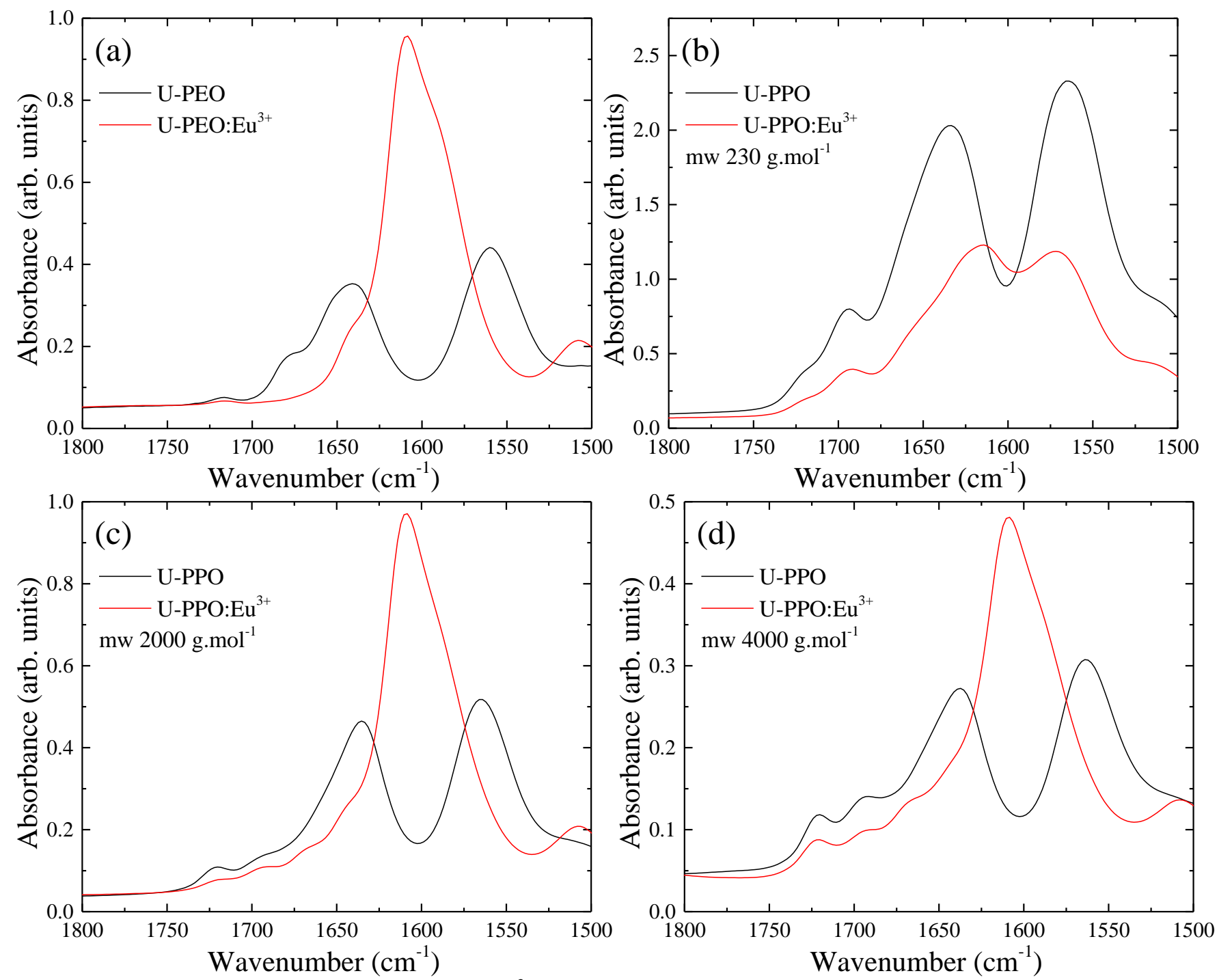

Figure 2: (2-columm fitting image) Effect of $\mathrm{Eu}^{3+}$ doping on the amide I and II regions of the FTIR spectra of OIH films for (a) U-PEO (mw = $1900 \mathrm{~g} \cdot \mathrm{mol}^{-1}$ ) and for U-PPO with mw of (b) 230, (c) 2000, and (d) $4000 \mathrm{~g} \cdot \mathrm{mol}^{-1}$.

\subsection{Effect of photooxidation on structural and nanostructural properties}

The chemical modifications resulting from exposure of the undoped and $\mathrm{Eu}^{3+}$-doped U-PEO and U-PPO hybrid samples to UV light irradiation resulted in important modifications of the FTIR spectra (Figure 3). The more important feature is the appearance of new bands in the carbonyl region at 1800-1500 $\mathrm{cm}^{-1}$. The spectra for the undoped U-PEO (Figure 3a) and U-PPO (Figure 3b) showed an intense band with a maximum at $1725 \mathrm{~cm}^{-1}$, together with a shoulder at $1750 \mathrm{~cm}^{-1}$. Previous studies of the photochemical behaviour of unhybridized polyethylene oxide (PEO) showed that these bands could be ascribed to the photooxidation products of the PEO chains, identified as formate $\left(1725 \mathrm{~cm}^{-1}\right)$ and ester $\left(1750 \mathrm{~cm}^{-1}\right)$ [33-36]. In the case of U-PPO (Figure 3b) the shoulder at $1750 \mathrm{~cm}^{-1}$ was less evident, suggesting a predominance of decomposition to formate product. For OIH:Eu ${ }^{3+}$ samples the band at around $1725 \mathrm{~cm}^{-1}$ (Figures 3c and 3d for U-PEO and U-PPO, respectively) was developed upon irradiation with faster rate for U-PEO: $\mathrm{Eu}^{3+}$ and comparable rate for U-PPO, U-PEO and the U-PPO:Eu ${ }^{3+}$. This feature 
suggests that the semicrystalline nature of the U-PEO coupled to the $\mathrm{Eu}^{3+}$ doping plays an import role on the photodegradation kinetics.

Moreover, slight modifications of the amide I $\left(1635 \mathrm{~cm}^{-1}\right)$ and amide II $\left(1560 \mathrm{~cm}^{-1}\right)$ bands of the urea linkage were observed during exposure of U-PEO and UPPO to UV light for $10 \mathrm{~h}$. Decreased intensity and splitting of the bands indicated an increasing participation of amide groups in hydrogen-bonded aggregates[10]. In the case of U-PEO:Eu ${ }^{3+}$ and UPPO:Eu ${ }^{3+}$, there was a decrease of the band at $1608 \mathrm{~cm}^{-1}$, which was assigned to a fingerprint of complexation of the $\mathrm{Eu}^{3+}$ ions by the urea bridges[20]. This suggested that photooxidation of the $\mathrm{OIH}: \mathrm{Eu}^{3+}$ samples led to a continuous dissociation of $\mathrm{Eu}^{3+}$ ions from the organic-inorganic interfaces of the U-PEO and U-PPO matrices.
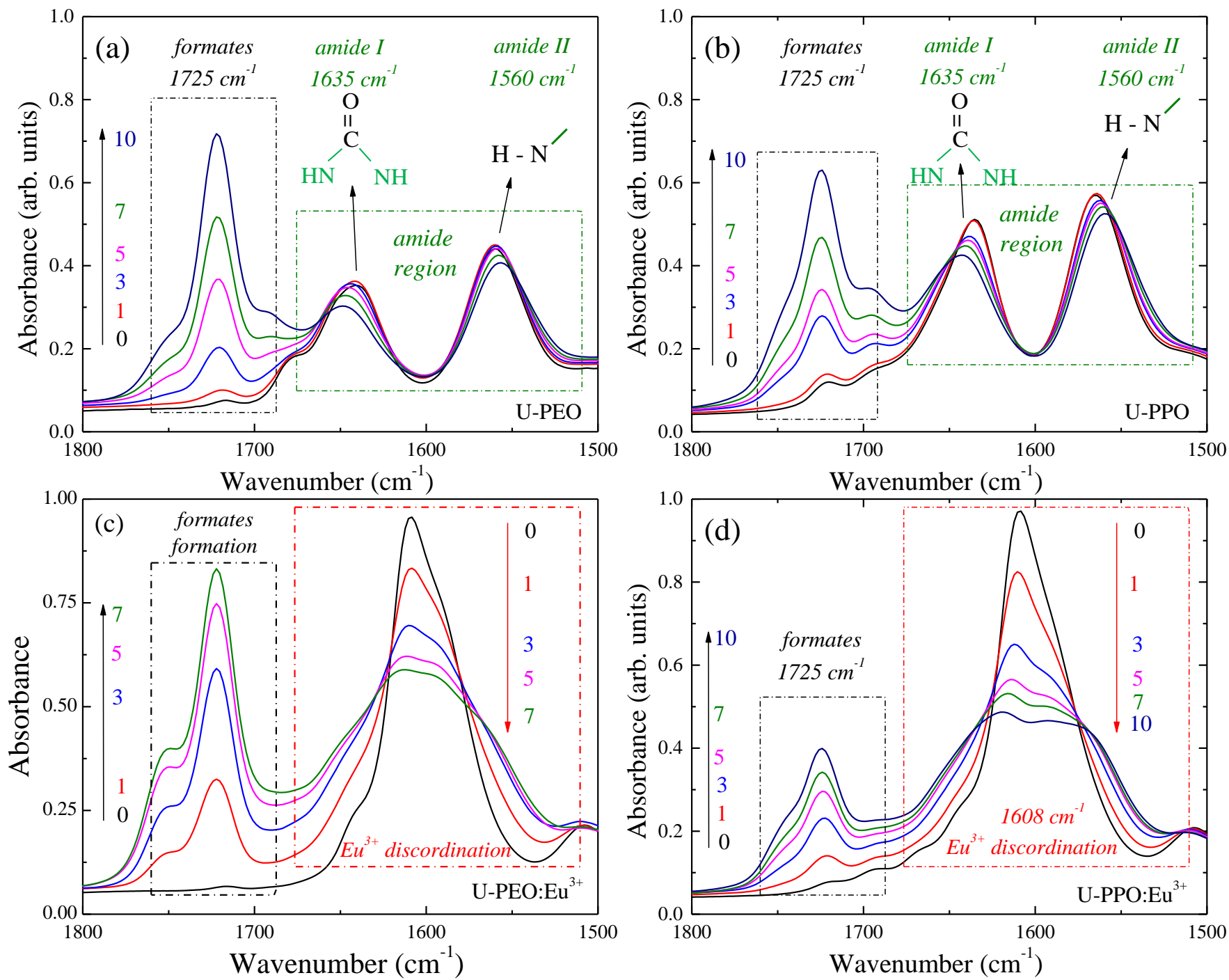

Figure 3: (2-columm fitting image) Room temperature IR spectra from 1800 to $1500 \mathrm{~cm}^{-1}$ of the OIH films during photooxidation: (a) U-PEO, (b) U-PPO, (c) U-PEO:Eu ${ }^{3+}$, and (d) U-PPO:Eu ${ }^{3+}$.

In order to identify the U-PE oxidation products, $\mathrm{NH}_{3}$ derivatization treatment of the photoaged films was performed according to the procedure described previously[33],[51]. The FTIR spectra of the photooxidized U-PEO:Eu ${ }^{3+}$ and U-PPO:Eu ${ }^{3+}$ films before and after $10 \mathrm{~h}$ reaction with $\mathrm{NH}_{3}$ are shown in Figure SI.2. After $\mathrm{NH}_{3}$ treatment, the FTIR spectrum of the photooxidized film showed a decrease of the absorption band at $1725 \mathrm{~cm}^{-1}$, together with the 
formation of three new absorption bands at 1690, 1640, and $1565 \mathrm{~cm}^{-1}$, related to the formation of amide from the reaction of ester such as formate with $\mathrm{NH}_{3}\left(\mathrm{HC}=\mathrm{O}-\mathrm{O}-\mathrm{CH}_{2}-+\mathrm{NH}_{3} \rightarrow 2 \mathrm{HN}-\mathrm{C}=\mathrm{O}-\right.$ $\mathrm{O}-\mathrm{CH}_{2}-$ ) and to the dissociation of urea complexed to $\mathrm{Eu}^{3+}$ ions. The $\mathrm{NH}_{3}$ reaction confirmed that the both $\mathrm{Eu}^{3+}$-loaded polyether hybrid materials produced similar photooxidation products.

The evolution of the $\mathrm{OIH}$ and $\mathrm{OIH}: \mathrm{Eu}^{3+}$ nanostructures, as a function of the UV light exposure time, was evidenced from the SAXS curves shown in Figure 4. The main effect observed following $\mathrm{Eu}^{3+}$ incorporation and photoaging was alteration of the peak attributed to the spatial correlation of regularly spaced siloxane cross-linked nodes[52]. After loading with Eu ${ }^{3+}$, this peak was shifted from 2.15 to $1.66 \mathrm{~nm}^{-1}$ for U-PEO and from 1.51 to $1.44 \mathrm{~nm}^{-1}$ for U-PPO, corresponding to increases of the average correlation distance between adjacent siloxane nodes (D $\left.=2 \pi / q_{\max }\right)$. Following $\mathrm{Eu}^{3+}$ incorporation this distance is displaced from 2.92 to $3.78 \mathrm{~nm}$ for UPEO and from 4.16 to $4.36 \mathrm{~nm}$ for U-PPO. The concomitant increased intensity of the correlation peak evidenced the increase of the electron density between the inorganic and the polymeric phases. These phenomena were due to the increase of the free volume of the polymeric matrix caused by the breaking of $\mathrm{H}$-bonding associations, together with the complexation of $\mathrm{Eu}^{3+}$ by the carbonyl oxygen of the amide group[20]. 

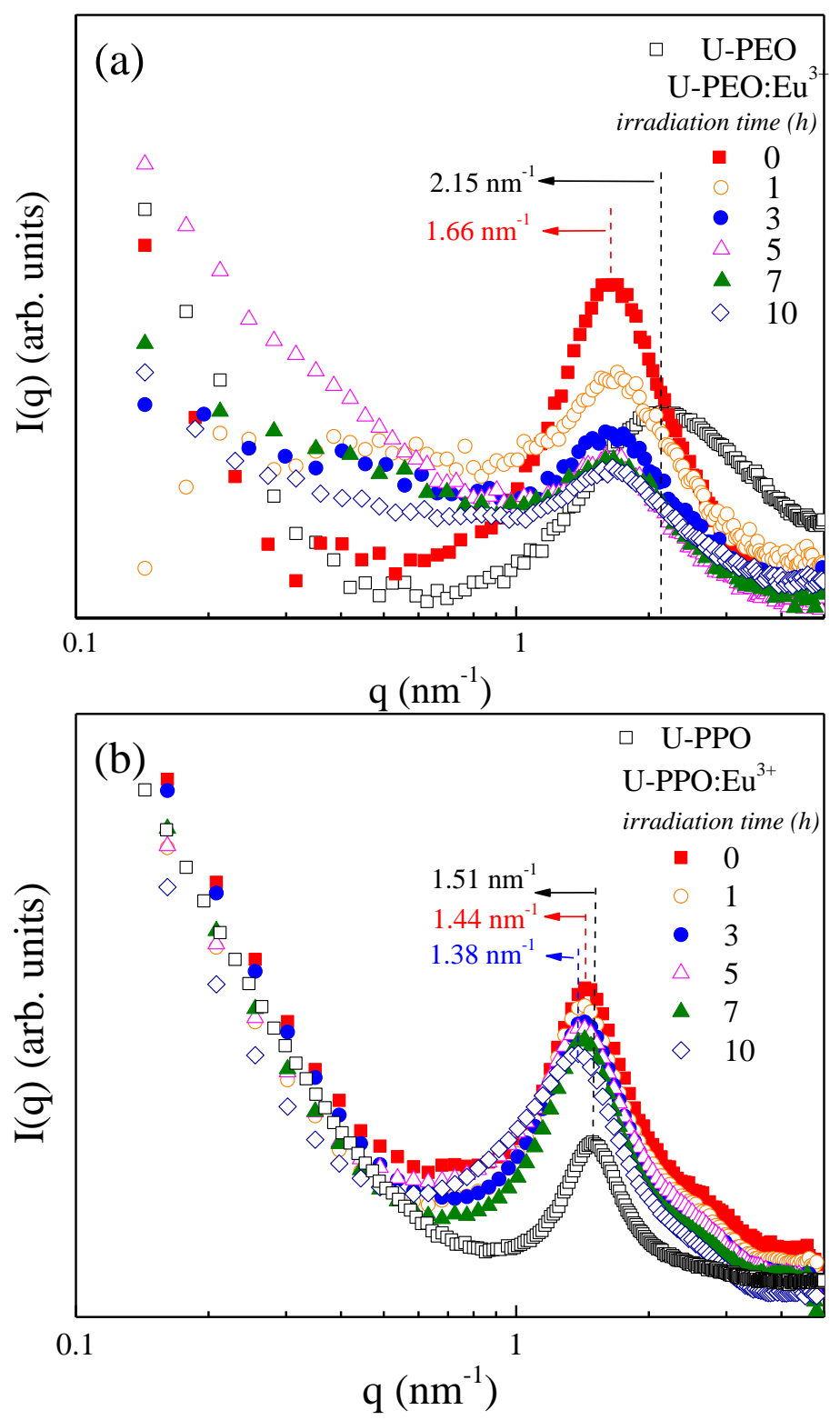

Figure 4: (single fitting image) SAXS curves, as a function of UV exposure time, for the $\mathrm{Eu}^{3+}$-doped hybrids compared to the undoped ones: (a) U-PEO and (b) U-PPO

In the case of U-PEO:Eu ${ }^{3+}$, the correlation peak intensity decreased as the UV exposure time increased. This could be ascribed to two effects, with (i) $\mathrm{Eu}^{3+}-\mathrm{O}_{\text {carb }}$ dissociation decreasing the electronic density contrast between the inorganic and organic moieties, and (ii) scission of the PEO chains leading to a decrease of the number of spatially correlated siloxane nodes. It can be seen from the curves in Figure 4a that after 3 h of UV exposure, the $\mathrm{I}\left(\mathrm{q}_{\max }\right)$ intensity was lower for U-PEO: $\mathrm{Eu}^{3+}$, compared to the undoped U-PEO host. In contrast, even after $10 \mathrm{~h}$ of UV exposure, the intensity of the U-PPO:Eu ${ }^{3+}$ correlation peak remained higher, compared to the UPPO matrix, as shown in Figure 4b. This difference revealed an important role played by the nature of the polymer (semicrystalline or amorphous; hydrophilic or hydrophobic), in terms of the sensitivity to photoaging. For semicrystalline and hydrophilic polymers (such as PEO), photoaging starts in the amorphous phase, due to the easy diffusion of oxygen through the unordered chains[53]. Accordingly, the observed decrease of the electron density contrast 
between the siloxane nodes and the polymeric matrix indicated a more compact structure resulting from increase of the crystalline phase fraction[54], caused by the scission of polyether chains in the amorphous phase. However, the U-PEO: $\mathrm{Eu}^{3+}$ nanostructure was preserved, as evidenced from the maintenance of the spatial correlation between the regularly spaced siloxane cross-linked nodes.

In order to understand the nanostructural modifications caused by the photoaging, it is important to note that after $10 \mathrm{~h}$ of $\mathrm{UV}$ exposure, the absorbance (A) value for the band at 1725 $\mathrm{cm}^{-1}$ (see Figure 3), ascribed to the photoaging products, was lower for U-PPO:Eu ${ }^{3+}(0.44)$ compared to U-PEO:Eu ${ }^{3+}(0.83)$. This indicated that the more intense $\mathrm{I}\left(\mathrm{q}_{\max }\right)$ decrease observed for U-PEO: $\mathrm{Eu}^{3}$ was due to degradation of the polyether chains. However, the effect of chain scission on the nanostructure of the amorphous U-PPO:Eu ${ }^{3+}$ could be seen from the slight displacement of the $\mathrm{q}_{\max }$ position from 1.44 to $1.37 \mathrm{~nm}^{-1}$, due to the formation of more compact structures [54]. In contrast, no systematic changes were observed in the U-PEO:Eu ${ }^{3+}$ correlation peak position following UV exposure, suggesting that the average correlation distance between two adjacent siloxane nodes of the already compact structure was less influenced by this effect, due to the semicrystalline nature of the material. Despite this complexity, the evolution of the growth of the relative area $\left(\mathrm{A}_{t} / \mathrm{A}_{10}\right)$ of the formate band at $1725 \mathrm{~cm}^{-1}$, as well as the decreases of the amide band at $1608 \mathrm{~cm}^{-1}$ and the SAXS peak $\left(\mathrm{S}_{\mathrm{t}} / \mathrm{S}_{0}\right)$, could be described by exponential growth $\left(\mathrm{y}_{\mathrm{t}} / \mathrm{y}_{10}=1+\exp (\mathrm{k} . \mathrm{t})\right)$ or decay $\left(\mathrm{y}_{\mathrm{t}} / \mathrm{y}_{0}=1-\exp (\mathrm{k} . \mathrm{t})\right)$ laws, as shown in Figure 5. This approach evidenced that for U-PPO: $\mathrm{Eu}^{3+}$, all the events occurred concomitantly, with comparable time constants (k) (Table 1), suggesting the existence of correlations between the processes occurring at nanoscopic and molecular length scales.

In contrast, for U-PEO: $\mathrm{Eu}^{3+}$, the different time constant values indicated the existence of a faster process that was probably governed by the facilitated transport of the oxidative species through the interface and the amorphous moieties of the semicrystalline U-PEO. This hypotheses was confirmed from the fusion enthalpies values founded from DSC measurements, with evidenced a decrease from $21 \%$ to $16 \%$ of the U-PEO crystalline phase fraction upon Eu ${ }^{3+}$ addition (Figure SI.3a). This decrease of crystallinity degree favors the diffusion of oxygen through the unordered chains, making ease the initiation of photooxidative degradation of the amorphous phase[55]. This fast degradation process leads to formation of low molecular weight products which can diffuse out the polymer matrix[56,57], decreasing the mass of amorphous polymer and increasing the crystallinity degrees during the first $3 \mathrm{~h}$ of UV light irradiation. The correlation between the increase of the crystallinity degree and the deaccelerated growth of formate production observed in this initial stage (Figure SI.3a and b) is consistent with the explanation based on the facilitated transport of oxidative species. In addition, the second increases of the format production rate coupled with a pronounced decrease of crystallinity degrees was observed in the advanced stage of photodegradation of U-PEO:Eu ${ }^{3+}$. These correlated features observed in the early and advanced stages are driven by the association of europium salt with the ether type oxygens atoms occurring at the initial addition? of europium salt and also by the continuous photo dissociation of urea- $\mathrm{Eu}^{3+}$ complexes. 

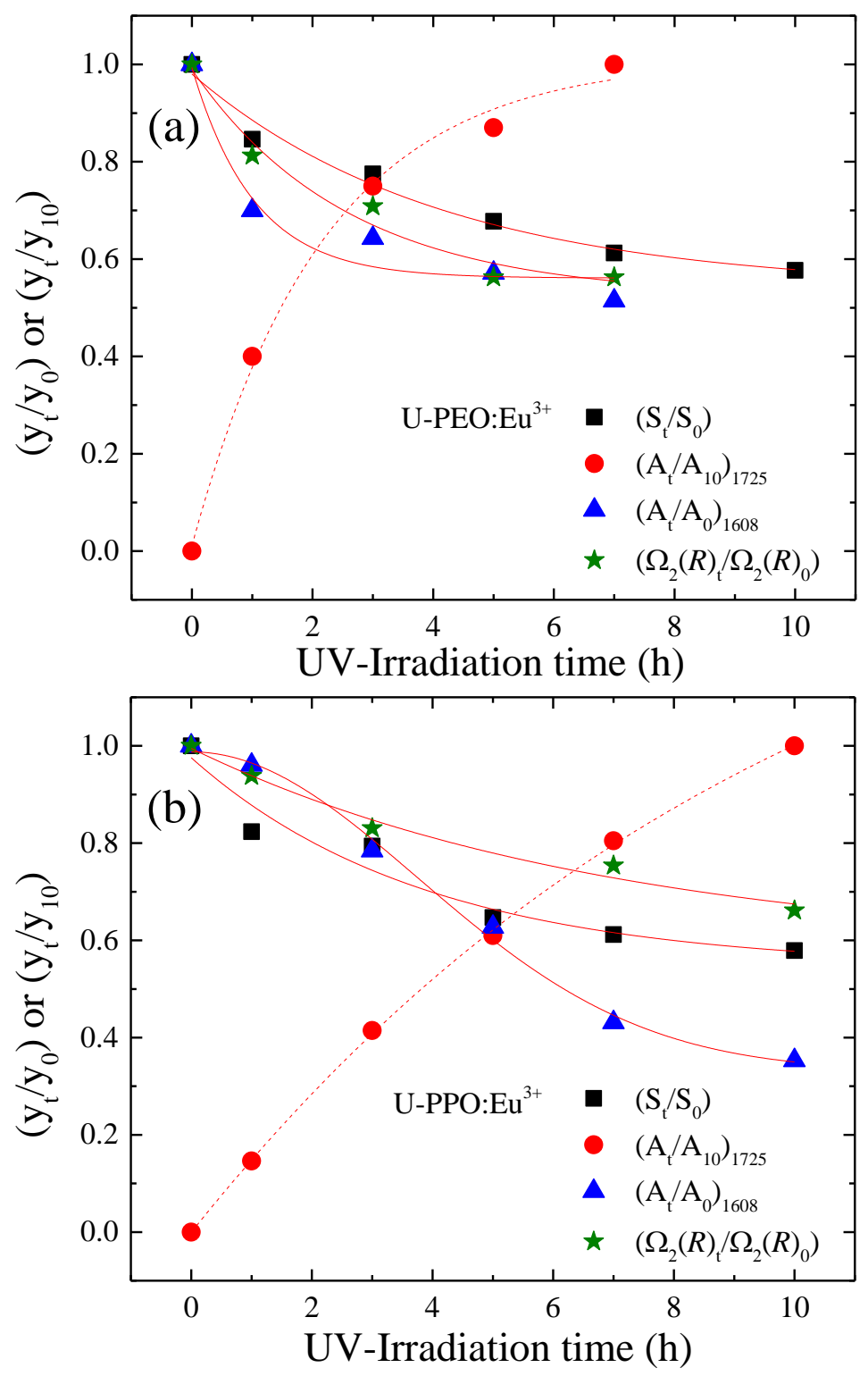

Figure 5: (single fitting image) Evolution of the relative areas of the SAXS correlation peak $\left(\mathrm{S}_{\mathrm{t}} / \mathrm{S}_{0}\right)$, the formate formation band at $1725 \mathrm{~cm}^{-1}\left(\mathrm{~A}_{\mathrm{t}} / \mathrm{A}_{10}\right)_{1725}$, the $\mathrm{Eu}^{3+}$-OIH decomplexation fingerprint band at $1608 \mathrm{~cm}^{-1}\left(\mathrm{~A}_{\mathrm{t}} / \mathrm{A}_{0}\right)_{1608}$, and the Judd-Ofted parameter ratio $\left(\Omega_{2}(R) t /\left(\Omega_{2}(\mathrm{R})_{0}\right)\right.$, as a function of the time of photooxidation, for (a) U-PEO:Eu ${ }^{3+}$ and (b) U-PPO:Eu ${ }^{3+}$. The continuous and dashed lines show the best fits of the exponential decay $\left(\mathrm{y}_{\mathrm{t}} / \mathrm{y}_{0}=1-\exp (\mathrm{k} . \mathrm{t})\right)$ and growth $\left(\mathrm{y}_{\mathrm{t}} / \mathrm{y}_{10}=1+\exp (\mathrm{k} . \mathrm{t})\right)$ laws, respectively.

\subsection{Effect of photooxidation on luminescence properties}

The effects of the photodegradation on the photoluminescence (PL) properties of the UPEO: $\mathrm{Eu}^{3+}$ and U-PPO:Eu ${ }^{3+}$ samples were investigated in the visible range. The photooxidation of the polymer and the decomplexation of $\mathrm{Eu}^{3+}$ ions from the hybrid host matrix could be confirmed by following the excitation (Figure 6) and emission (Figure 7) spectra recorded as a function of the UV irradiation time. As shown in Figure 1b, the antenna effect between the organic ligand and the $\mathrm{Eu}^{3+}$ ions was only efficient for the U-PPO: $\mathrm{Eu}^{3+}$ sample, resulting in a broad band centred at $365 \mathrm{~nm}$ in the excitation spectrum. However, the excitation spectra for the photooxidized UPPO: $\mathrm{Eu}^{3+}$ (Figure 6b) revealed a dramatic decrease of intensity after $1 \mathrm{~h}$ of exposure to UV irradiation. This was accompanied by increased intensities of the bands located at 380, 395, and 
$465 \mathrm{~nm}$, attributed to the $\mathrm{Eu}^{3+}$ intra-configurational transitions ${ }^{7} \mathrm{~F}_{0} \rightarrow{ }^{5} \mathrm{~L}_{7},{ }^{7} \mathrm{~F}_{0} \rightarrow{ }^{5} \mathrm{~L}_{6}$, and ${ }^{7} \mathrm{~F}_{0} \rightarrow$ ${ }^{5} \mathrm{D}_{2}$, respectively[17]. These results were consistent with degradation of the organic moiety and consequent dissociation of $\mathrm{Eu}^{3+}$ ions from the hybrid host matrix. The low intensity found for UPEO: $\mathrm{Eu}^{3+}$ could be explained by the nature of the polymer, especially the hydrophilic properties, with the water molecules that are typically found in interaction with the PEO backbone acting to quench the $\mathrm{Eu}^{3+}$ photoluminescence[58].
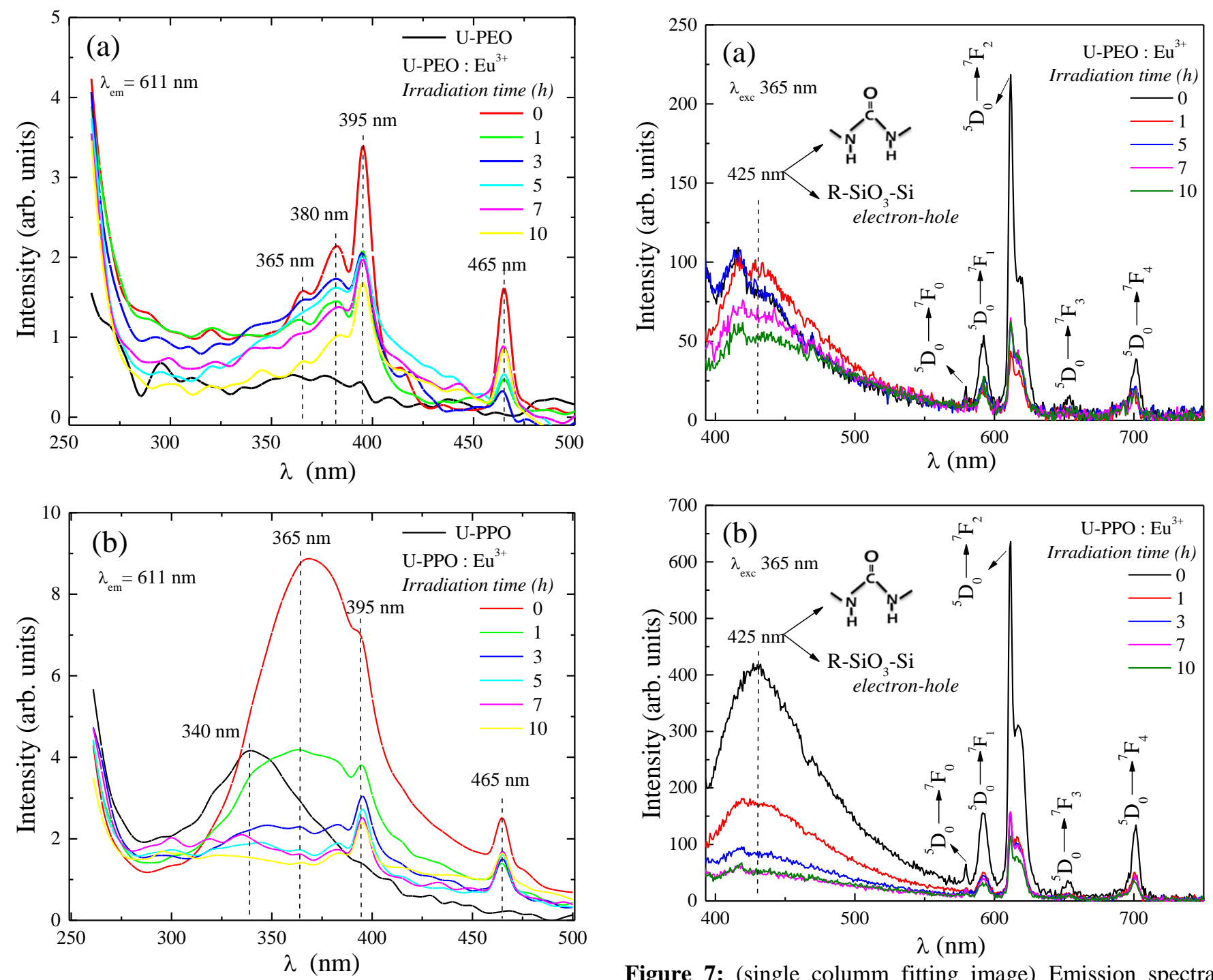

Figure 6: (single columm fitting image) Excitation spectra of (a) U-PEO:Eu ${ }^{3+}$ and (b) U-PPO:Eu ${ }^{3+}$ exposed to UV irradiation for different times.

Figure 7: (single columm fitting image) Emission spectra recorded at RT for (a) U-PEO:Eu ${ }^{3+}$ and (b) U-PPO:Eu ${ }^{3+}$ exposed to UV irradiation for different times.

The emission spectra recorded with excitation at $365 \mathrm{~nm}$ (Figure 7) revealed decreased intensities of both the broad band at $425 \mathrm{~nm}$ and the narrow lines $\left({ }^{5} \mathrm{D}_{0} \rightarrow{ }^{7} \mathrm{~F}_{\mathrm{J}}\right)$. The decreased intensity of the blue band could be attributed to photooxidation of the polyether chains, which decreased the number of spatially correlated siloxane nodes, as revealed by the reduced area of the SAXS peak shown in Figure 5. This hindered the complexation of $\mathrm{Eu}^{3+}$ to urea bridges, as observed for the shorter chain U-PPO: $\mathrm{Eu}^{3+}$ (Figure 2a). The photodegradation of the organic moieties led to $\mathrm{OIH}-\mathrm{Eu}^{3+}$ dissociation at the organic-inorganic interface. These phenomena could 
be detected from the change of the intensity of the so-called "hypersensitive" transition[59,60], ${ }^{5} \mathrm{D}_{0} \rightarrow{ }^{7} \mathrm{~F}_{2}$, as a function of the UV irradiation time.

The luminescence intensity ratio, $R=\left({ }^{5} \mathrm{D}_{0} \rightarrow{ }^{7} \mathrm{~F}_{2}\right) /\left({ }^{5} \mathrm{D}_{0} \rightarrow{ }^{7} \mathrm{~F}_{1}\right)$, is known as the asymmetry ratio. Higher values of $R$ indicate lower symmetry around the trivalent europium ions. The JuddOfelt parameter $\left(\Omega_{2}\right)$ and $R$ provide similar information about the physical nature of the bonding between $\mathrm{Eu}^{3+}$ ions and the surrounding ligands, explaining the short range effects on the local structure around the $\mathrm{Eu}^{3+}$ ions[61-63]. Similar values of the $\Omega_{2}(R)$ parameter $(\sim 4)$ were observed for the non-irradiated PEO: $\mathrm{Eu}^{3+}$ and PPO: $\mathrm{Eu}^{3}$ samples, indicating that the $\mathrm{Eu}^{3+}$ atoms occupied very similar coordination (semicrystalline or amorphous)[64]. These $\Omega_{2}(\mathrm{R})$ values were higher than those observed elsewhere for $\mathrm{Eu}^{3+}$ incorporated in several oxide glasses and polymers, including PEO and PPO[9], indicating that the symmetry of the $\mathrm{Eu}^{3+}$ sites was distorted[20]'[64]. However, after $10 \mathrm{~h}$ of UV exposure, the $\Omega_{2}(R)$ values decreased from $\sim 4$ to $\sim 3$ and $\sim 2$ for UPPO: $\mathrm{Eu}^{3+}$ and U-PEO:Eu ${ }^{3+}$, respectively. These decreases occurred continuously during the irradiation time, following trends comparable to the decreasing intensity of the broad blue band. This behaviour suggested that the photooxidation of the polyether chains led to modification of the surrounding $\mathrm{Eu}^{3+}$ ligands, resulting in decreases of the asymmetry parameter.

The most noteworthy finding was the good correlation between the nanoscopic features and the local environment around the $\mathrm{Eu}^{3+}$ emitter, as evidenced by the comparable temporal evolution of the relative SAXS peak area values $\left(\mathrm{S}_{\mathrm{t}} / \mathrm{S}_{0}\right)$ and $\Omega_{2}(R)_{\mathrm{t}} / \Omega_{2}(R)_{0}$ (Figure 5). These two functions were described by exponential decay laws with comparable time constants (Table 1), clearly evidencing the sensitivity of the photoluminescence to the elimination/formation of the hydrogenbonded urea-polyether array during photooxidation of the PEO and PPO chains. These nanoscopic properties arising from the photoinduced degradation of ureasil-polyether can be exploited in the development of new transparent, flexible, and biocompatible UV dosimeters and sensors.

Table 1: Time constants $(k)$ of the fitted exponential growth or decay law curves $\left(\mathrm{y}_{3_{+}} / \mathrm{y}_{10}=1 \pm \exp (\mathrm{k} . \mathrm{t})\right)$ for the relative area of the SAXS correlation peak, the Judd-Ofelt parameter ratio $\left(\Omega_{2}(\mathrm{R})_{\mathrm{t}} /\left(\Omega_{2}(\mathrm{R})_{0}\right)\right.$, the Eu ${ }^{3+}$-OIH decomplexation fingerprint band at $1608 \mathrm{~cm}^{-1}$, and the formate formation band at $1725 \mathrm{~cm}^{-1}$ (undoped in brackets), as a function of photooxidation time, for UPEO: $\mathrm{Eu}^{3+}$ and U-PPO: $\mathrm{Eu}^{3+}$.

\begin{tabular}{lcc}
\hline \multicolumn{1}{c}{ Relative area from } & \multicolumn{2}{c}{ Time constant $K\left(\mathrm{~h}^{-1}\right)$} \\
& U-PEO:Eu & U-PPO:Eu \\
& 0.25 & 0.26 \\
\hline SAXS & 0.39 & 0.15 \\
PL $\left(\Omega_{2}(R)\right)$ & 0.97 & 0.07 \\
IR @ $1608 \mathrm{~cm}^{-1}$ & $0.45(0.33)$ & $0.10(0.10)$ \\
IR @ $1725 \mathrm{~cm}^{-}$ & \\
\hline
\end{tabular}

\section{Conclusions}

Different ureasil-polyether materials based on polyethylene oxide (U-PEO) and polypropylene oxide (U-PPO), undoped and loaded with $\mathrm{Eu}^{3+}$, were successfully prepared by the sol-gel route in the forms of monoliths and thin films (50 $\mu \mathrm{m}$ thick). The FTIR spectra confirmed the preferential complexation of $\mathrm{Eu}^{3+}$ by the carbonyl group $\left(\mathrm{O}_{\text {carb }}\right)$ of the urea linkage. The best photoluminescence properties were found for a doping level equivalent to $\left[\mathrm{O}_{\text {carb }}\right] /\left[\mathrm{Eu}^{3+}\right]=3$. The PL results evidenced loss of the ligand-to-metal charge transfer when the $\mathrm{Eu}^{3+}$ cations were 
unable to disrupt the strong hydrogen-bonded urea/urea aggregates formed using shorter chain UPPO (230 g.mol $\left.{ }^{-1}\right)$ and semicrystalline U-PEO (1900 g.mol $\left.{ }^{-1}\right)$.

Formate was the main photoproduct formed following exposure of U-PEO and U-PPO to artificial UV light, revealing a photooxidation process quite similar to the observed for conventional PEO and PPO materials. In addition, the urea linkages present at the organicinorganic interface are weakly dependent on the time of UV light exposure as demonstrated by slight modifications of the amide bands.

The $\mathrm{Eu}^{3+}$ addition to semicrystalline U-PEO allows to an increase of the amorphous phase with accelerate initial formation of the formate, the main photooxidation product. The photoinduced dissociation of $\mathrm{Eu}^{3+}$ complexed to the urea and consequent association to the ether oxygen atoms of the polymer chains favors the propagation of depolymerisation reactions in the advanced stages.

The continuous recovery of the hydrogen bond of the amide structure evidenced the $\mathrm{Eu}^{3+}$ decomplexation induced by exposure to intense UV light. This induces the decreased intensity of the broad green-blue band, as revelled by PL analyses conducted as a function of the UV exposure time.

The photooxidation of the polyether chains resulted in concomitant decreases of the spatially correlated siloxane nodes and the Judd-Ofelt parameter, $\Omega_{2}(\mathrm{R})$. The kinetic evolution of these parameters could be described by exponential laws with comparable time constants, evidencing the sensitivity of the $\mathrm{Eu}^{3+}$ photoluminescence to the elimination/formation of the hydrogenbonded urea-polyether array during the photooxidation of the PPO chains. In contrast, for U$\mathrm{PEO}: \mathrm{Eu}^{3+}$ different time constant values were obtained, due to the existence of a faster process governed by the facilitated transport of the oxidative species through the amorphous moieties of the semicrystalline U-PEO.

\section{Acknowledgements}

This work was supported by the Brazilian agency CNPq (grants 142495/2013-1, 203031/2015-6, and 401679/2013-6). This study is a collaborative research project of the members of the National Institute on Advanced Eco-Efficient Cement-Based Technologies (FAPESP INCT 2014 50948-3; 465593/2014-3). The authors thank the Brazilian Synchrotron Light Laboratory (LNLS) in Campinas for use of the SAXS1 beamline.

\section{Notes and references}

[1] H. Kataoka, S. Omagar, Y. Takabatake, Drastically Improved Durability and Efficiency of Silicon Solar Cells Using Hyper-Stable Lanthanide Coordination Polymer Beads, Bull. Chem. Soc. Jpn. 3 (2015) 103-109. doi:10.1246/bcsj.20150325.

[2] D. Druvari, N.D. Koromilas, G.C. Lainioti, G. Bokias, G. Vasilopoulos, A. Vantarakis, I. Baras, N. Dourala, J.K. Kallitsis, Polymeric Quaternary Ammonium-Containing Coatings with Potential Dual Contact-Based and Release-Based Antimicrobial Activity, Appl. Mater. Interfaces. 8 (2016) 35593-35605. doi:10.1021/acsami.6b14463.

[3] T. Abohalkuma, J. Telegdi, Corrosion protection of carbon steel by special phosphonic acid nanolayers, Mater. Corros. (2015) 1382-1390. doi:10.1002/maco.201508304.

[4] B. Yan, Recent progress in photofunctional lanthanide hybrid materials, RSC Adv. 2 (2012) 9304- 
9324. doi:10.1039/c2ra20976d.

[5] J. Feng, H. Zhang, Hybrid Materials Based oon Lanthanide Organic Complexes : a review, Chem. Soc. Rev. 42 (2013) 387-410. doi:10.1039/c2cs35069f.

[6] M. Faustini, L. Nicole, E. Ruiz-Hitzky, C. Sanchez, History of Organic-Inorganic Hybrid Materials: Prehistory, Art, Science, and Advanced Applications, Adv. Funct. Mater. 28 (2018) 130. doi:10.1002/adfm.201704158.

[7] S. Parola, B. Julián-López, L.D. Carlos, C. Sanchez, Optical Properties of Hybrid OrganicInorganic Materials and their Applications, Adv. Funct. Mater. 26 (2016) 6506-6544. doi:10.1002/adfm.201602730.

[8] C. Sanchez, P. Belleville, M. Popall, L. Nicole, Applications of advanced hybrid organic-inorganic nanomaterials: from laboratory to market, Chem. Soc. Rev. 40 (2011) 696-753. doi:10.1039/c0cs00076k.

[9] K. Binnemans, Lanthanide-Based Luminescent Hybrid Materials, Chem. Rev. 109 (2009) 42834374.

[10] K. Binnemans, Interpretation of europium (III) spectra, Coord. Chem. Rev. 295 (2015) 1-45. doi:10.1016/j.ccr.2015.02.015.

[11] Q. Li, Multifunctional Ionogels Incorporated with Lanthanide (Eu3+, Tb3+) Complexes Covalently Modified Multi-Walled Carbon Nanotubes, Polymer (Guildf). 10 (2018) 1099-1108. doi:10.3390/polym10101099.

[12] K. Dahmouche, L.D. Carlos, V. de Zea Bermudez, R.A. Sá Ferreira, C. V. Santilli, A.F. Craievich, Structural modelling of Eu3+-based siloxane-poly(oxyethylene) nanohybrids, J. Mater. Chem. 11 (2001) 3249-3257. doi:10.1039/b104822h.

[13] C. Molina, K. Dahmouche, C. V. Santilli, A.F. Craievich, S.J.L. Ribeiro, Structure and luminescence of Eu3+-doped class I siloxane-poly(ethylene glycol) hybrids, Chem. Mater. 13 (2001) 2818-2823. doi:10.1021/cm0012320.

[14] M. Fernandes, V.D.Z. Bermudez, L.D. Carlos, A. Charas, J. Morgado, M.M. Silva, M.J. Smith, Highly Photostable Luminescent Poly ( E -caprolactone ) siloxane Biohybrids Doped with Europium Complexes, Chem. Mater. 19 (2007) 3892-3901.

[15] S.C. Nunes, V.D.Z. Bermudez, J. Cybinska, R.A. Sa, J. Legendziewicz, L.D. Carlos, M.M. Silva, M.J. Smith, D. Ostrovskii, J. Rocha, Structure and photoluminescent features of di-amide crosslinked alkylene - siloxane hybrids, J. Mater. Chem. 15 (2005) 3876-3886. doi:10.1039/b505372m.

[16] X. Huang, Q. Wang, X. Yan, J. Xu, W. Liu, Q. Wang, Y. Tang, Encapsulating a Ternary Europium Complex in a Silica / Polymer Hybrid Matrix for High Performance Luminescence Application, J. Phys. Chem. C. 115 (2011) 2332-2340. doi:10.1021/jp109644j.

[17] R.A.S. Ferreira, L.D. Carlos, R.R. Gonçalves, S.J.L. Ribeiro, V.D.Z. Bermudez, Energy-Transfer Mechanisms and Emission Quantum Yields In Eu3+ -Based Siloxane-Poly ( oxyethylene ) Nanohybrids, Chem. Mater. 13 (2001) 2991-2998. doi:10.1021/cm010311o.

[18] B. Li, H.M. Wen, Y. Cui, G. Qian, B. Chen, Multifunctional lanthanide coordination polymers, Prog. Polym. Sci. 48 (2015) 40-84. doi:10.1016/j.progpolymsci.2015.04.008.

[19] V. de Z. Bermudez, D. Ostrovskii, M.C. Gonçalves, S. Lavoryk, L.D. Carlos, R.A.S. Ferreira, Eu3+ Coordination in an Organic/Inorganic Hybrid Matrix with Methyl End-Capped Short Polyether Chains, J. Phys. Chem. B. 109 (2005) 7110-7119.

[20] G. Palácio, S.H. Pulcinelli, R. Mahiou, D. Boyer, G. Chadeyron, C. V. Santilli, Coupling Photoluminescence and Ionic Conduction Properties Using the Different Coordination Sites of Ureasil-Polyether Hybrid Materials, ACS Appl. Mater. Interfaces. 10 (2018) 37364-37373. doi:10.1021/acsami.8b11149.

[21] C. Wei, L. Ma, H.B. Wei, Z.W. Liu, Z.Q. Bian, C.H. Huang, Advances in luminescent lanthanide complexes and applications, Sci. China Technol. Sci. 61 (2018) 1265-1285. doi:10.1007/s11431017-9212-7. 
[22] J. Xu, A. Gulzar, P. Yang, H. Bi, D. Yang, S. Gai, F. He, J. Lin, B. Xing, D. Jin, Recent advances in near-infrared emitting lanthanide-doped nanoconstructs: Mechanism, design and application for bioimaging, Coord. Chem. Rev. 381 (2019) 104-134. doi:10.1016/j.ccr.2018.11.014.

[23] J.J. Wang, P.P. Si, M.J. Liu, Y. Chen, S.X. Yu, M. Lu, S.Y. Wang, B. Li, P.P. Li, R.C. Zhang, Selective fluorescent sensing and photodegradation properties of $\mathrm{Tb}$ (III)-based MOFs with different bulky backbone ligands, Polyhedron. 157 (2019) 63-70. doi:10.1016/j.poly.2018.09.066.

[24] G. Lan, K. Ni, W. Lin, Nanoscale metal-organic frameworks for phototherapy of cancer, Coord. Chem. Rev. 379 (2019) 65-81. doi:10.1016/j.ccr.2017.09.007.

[25] Z. Zhou, J. Gu, X. Qiao, H. Wu, H. Fu, L. Wang, H. Li, L. Ma, Double protected lanthanide fluorescence core@shell colloidal hybrid for the selective and sensitive detection of ClO-, Sensors Actuators, B Chem. 282 (2019) 437-442. doi:10.1016/j.snb.2018.11.103.

[26] S. Giancaterina, A. Rossi, A. Rivaton, J.L. Gardette, Photochemical evolution of poly ( ether ether ketone ), Polym. Degrad. Stab. 68 (2000) 133-144.

[27] B. Randy, Photodegradation and photo-oxidation of synthetic polymers, J. Anal. Appl. Pyrolysis. 15 (1989) 237-247.

[28] C. Rouillon, P. Bussiere, E. Desnoux, S. Collin, C. Vial, S. Therias, J.-L. Gardette, Is carbonyl index a quantitative probe to monitor polypropylene photodegradation ?, Polym. Degrad. Stab. 128 (2016) 200-208. doi:10.1016/j.polymdegradstab.2015.12.011.

[29] G. Lubineau, A. Rahaman, A review of strategies for improving the degradation properties of laminated continuous-fiber / epoxy composites with carbon-based nanoreinforcements, Carbon N. Y. 50 (2012) 2377-2395. doi:10.1016/j.carbon.2012.01.059.

[30] J.R. White, A. Turnbull, Weathering of polymers : mechanisms of degradation and stabilization , testing strategies and modelling, J. Mater. Sci. 29 (1994) 584-613.

[31] M. Iring, F. Tudos, Thermal Oxidation of Polyethylene and Polypropylene: Effects of Chemical Structure and Reaction Conditions on the Oxidation Process, Prog. Polym. Sci. 15 (1990) 217-262.

[32] M.J. Caulfield, G.G. Qiao, D.H. Solomon, Some Aspects of the Properties and Degradation of Polyacrylamides, Chem. Rev. 102 (2002) 3067-3083. doi:10.1021/cr010439p.

[33] S. Morlat, J. Gardette, Phototransformation of water-soluble polymers . I : photo- and thermooxidation of poly(ethylene oxide) in solid state, Polymer (Guildf). 42 (2001) 6071-6079.

[34] S. Morlat, J. Gardette, Phototransformation of water-soluble polymers . Part II : photooxidation of poly ( ethylene oxide ) in aqueous solution, Polymer (Guildf). 44 (2003) 7891-7897. doi:10.1016/j.polymer.2003.10.022.

[35] F. Hassouna, G. Mailhot, S. Morlat-therias, J. Gardette, Photochemical behaviour of poly (ethylene oxide) (PEO) in aqueous solution : Influence of iron salts, J. Photochem. Photobiol. A Chem. 195 (2008) 167-174. doi:10.1016/j.jphotochem.2007.09.019.

[36] F. Hassouna, S. Thérias-Morlat, G. Mailhot, J.L. Gardette, Influence of water on the photodegradation of poly ( ethylene oxide ), Polym. Degrad. Stab. 92 (2007) 2042-2050. doi:10.1016/j.polymdegradstab.2007.07.016.

[37] S.P. Vijayalakshmi, G. Madras, Photocatalytic Degradation of Poly (ethylene oxide) and Polyacrylamide, J. Appl. Polym. Sci. 100 (2006) 3997-4003. doi:10.1002/app.23190.

[38] C. V Santilli, L.A. Chiavacci, L. Lopes, S.H. Pulcinelli, A.G. Oliveira, Controlled Drug Release from Ureasil - Polyether Hybrid Materials, Chem. Mater. (2009) 463-467.

[39] S. Morlat-therias, E. Fanton, J. Gardette, S. Peeterbroeck, M. Alexandre, P. Dubois, Polymer / carbon nanotube nanocomposites : Influence of carbon nanotubes on EVA photodegradation, Polym. Degrad. Stab. 92 (2007) 1873-1882. doi:10.1016/j.polymdegradstab.2007.06.021.

[40] M.P. Zaldivar, C. V Santilli, C.A.P. Covas, S.H. Pulcinelli, Thermal properties, nanoscopic structure and swelling behavior of chitosan /( ureasil - polyethylene oxide hybrid ) blends, J. Therm. Anal. Calorim. 130 (2017) 791-798. doi:10.1007/s10973-017-6454-6.

[41] S.J.L. Ribeiro, K. Dahmouche, C.A. Ribeiro, C. V Santilli, S.H. Pulcinelli, Study of Hybrid Silica- 
Polyethyleneglycol Xerogels by Eu3+ Luminescence Spectroscopy, J. Sol-Gel Sci. Technol. 432 (1998) 427-432. doi:10.1023/A:1008673211834.

[42] V. de Zea Bermudez, R.A. Sá Ferreira, L.D. Carlos, C. Molina, K. Dahmouche, S.J.L. Ribeiro, Coordination of Eu3+ Ions in Siliceous Nanohybrids Containing Short Polyether Chains and Bridging Urea Cross-links, J. Phys. Chem. B. 105 (2001) 3378-3386. doi:10.1021/jp002665t.

[43] L.D. Carlos, V.D.Z. Bermudez, V.S. Amaral, S.C. Nunes, N.J.O. Silva, R.A.S. Ferreira, J. Rocha, C. V Santilli, D. Ostrovskii, Nanoscopic Photoluminescence Memory as a Fingerprint of Complexity in Self-Assembled Alkyl / Siloxane Hybrids **, Adv. Mater. 19 (2007) 341-348. doi:10.1002/adma.200601435.

[44] L.D. Carlos, R.A.S. Ferreira, R.N. Pereira, M. Assunção, V.D.Z. Bermudez, White-Light Emission of Amine-Functionalized Organic / Inorganic Hybrids : Emitting Centers and Recombination Mechanisms, J. Phys. Chem. B. 108 (2004) 14924-14932. doi:10.1021/jp049052r.

[45] S.S. Nobre, X. Cattoen, R.A.S. Ferreira, C. Carcel, V.D.Z. Bermudez, M. Wong, C. Man, L.D. Carlos, I. Charles, Eu3+-Assisted Short-Range Ordering of Photoluminescent Bridged Silsesquioxanes, Chem. Mater. 22 (2010) 3599-3609. doi:10.1021/cm1009042.

[46] S. Nobre, P. Lima, R.A. Sa, R.O. Freire, L. Fu, U. Pischel, D.Z. Bermudez, L.D. Carlos, Energy Transfer and Emission Quantum Yields of Organic - Inorganic Hybrids Lacking Metal Activator Centers, J. Phys. Chem. C. 111 (2007) 3275-3284.

[47] G.M. C, V.D.Z. Bermudez, R.A. Sa, L.D. Carlos, D. Ostroviskii, J. Rocha, Optically Functional Di-Urethanesil Nanohybrids Containing Eu3+ Ions, Chem. Mater. 16 (2004) 2530-2543.

[48] L.D. Gonçalves, M. C.; Bermudez, V. De Zea; Ostrovskii, D.; Carlos, Infrared and Raman Spectroscopic Investigation of Eu3+-Doped Mono and Di-Urethanesil Hybrid Siliceous Materials, Ionics (Kiel). 8 (2002) 62-72.

[49] M.C. Gonçalves, V.D.Z. Bermudez, R.A.S. Ferreira, D. Ostrovskii, L.D. Carlos, Di-Urethane Cross-linked Poly(oxyethylene)/Siloxane Nanohybrids Doped With Eu(CF3SO3)3, Mater. Res. Soc. 847 (2005) 3-8.

[50] M. Fernandes, P.C. Barbosa, M.M. Silva, M.J. Smith, V. De Zea, Di-ureasil hybrids doped with LiBF4: Spectroscopic study of the ionic interactions and hydrogen bonding, Mater. Chem. Phys. 129 (2011) 385-393. doi:10.1016/j.matchemphys.2011.04.030.

[51] S. Morlat, N. Cezard, B. Loubinoux, J. Philippart, J. Gardette, Mechanisms of photooxidation of polyglycerol, Polym. Degrad. Stab. 72 (2001) 199-208.

[52] K. Dahmouche, C.V. Santilli, S.H. Pulcinelli, A.F. Craievich, Small-Angle X-ray Scattering Study of Sol-Gel-Derived Siloxane-PEG and Siloxane-PPG Hybrid Materials, J. Phys. Chem. B. 103 (1999) 4937-4942. doi:10.1021/jp984605h.

[53] Z. Shen, G.P. Simon, Y. Cheng, Comparison of solution intercalation and melt intercalation of polymer-clay nanocomposites, Polymer (Guildf). 43 (2002) 4251-4260.

[54] E.F. Molina, C.R. Nogueira, L.A. Chiavacci, S.H. Pulcinelli, Ureasil - polyether hybrid blend with tuneable hydrophilic / hydrophobic features based on U-PEO1900 and U-PPO400 mixtures, J. SolGel Sci. Techonology. 70 (2014) 317-328. doi:10.1007/s10971-014-3300-1.

[55] H. Kaczmarek, A. Sionkowska, A. Kaminska, J. Kowalonek, M. Swiatek, A. Szalla, The influence of transition metal salts on photo-oxidative degradation of poly ( ethylene oxide ) a, Polym. Degrad. Stab. 73 (2001) 437-441.

[56] S.P. Vijayalakshmi, G. Madras, Photocatalytic Degradation of Poly ( ethylene oxide ) and Polyacrylamide, J. Appl. Polym. Sci. (2006) 3997-4003. doi:10.1002/app.23190.

[57] A. Kaminska, H. Kaczmarek, J. Kowalonek, Cobalt ( II ) chloride catalysed oxidative degradation of poly ( ethylene oxide ) by a short wavelength UV-radiation, Polymer (Guildf). 40 (1999) 57815791.

[58] F. Wang, D. Liu, J. Li, M. Ma, Molecular Engineering of Host Materials for High-Performance Phosphorescent OLEDs : Zig-Zag Conformation with 3D Gridding Packing Mode Facilitating 
Charge Balance and Quench Suppression, Adv. Funct. Mater. 28 (2018) 1803193-1803205. doi:10.1002/adfm.201803193.

[59] L.D. Carlos, R.A.S. Ferreira, M.C. Gonçalves, V.D.Z. Bermudez, Local coordination of Eu(III) in organic / inorganic amine functionalized hybrids, J. Alloys Compd. 374 (2004) 50-55. doi:10.1016/j.jallcom.2003.11.063.

[60] C. Sanchez, C. Boissiere, S. Cassaignon, C. Chaneac, O. Durupthy, M. Faustini, D. Grosso, L. Nicole, D. Portehault, F. Ribot, L. Rozes, C. Sassoye, Molecular Engineering of Functional Inorganic and Hybrid Materials, Chem. Mater. 26 (2014) 221-238. doi:10.1021/cm402528b.

[61] G.S. OFELT, Intensities of Crystal Spectra of Rare- Earth Ions, J. Phys. Chem. 511 (1962) 511520. doi:10.1063/1.1701366.

[62] S. Su, W. Chen, C. Qin, S. Song, Z. Guo, G. Li, X. Song, M. Zhu, S. Wang, Z. Hao, H. Zhang, Lanthanide Anionic Metal - Organic Frameworks Containing Semirigid Tetracarboxylate Ligands: Structure, Photoluminescence, and Magnetism, Cryst. Growth Des. 12 (2012) 1808-1815. doi:10.1021/cg201283a.

[63] G. Law, K. Wong, Y. Yang, Q. Yi, G. Jia, W. Wong, P.A. Tanner, Structural Characterization of Shielded Isomeric Europium Complexes with Metal - Metal Contact, Inorg. Chem. 46 (2007) 9754-9759. doi:10.1021/ic701162j.

[64] S. Yi, Q. Li, H. Liu, X. Chen, Reverse Lyotropic Liquid Crystals from Europium Nitrate and P123 with Enhanced Luminescence E ffi ciency, J. Phys. Chem. B. 118 (2014) 11581-11590. doi:10.1021/jp507745s. 